\title{
Evaluation of the therapeutic effect of methylene blue on the liver of rats submitted to ischemia and reperfusion ${ }^{1}$
}

Orlando Castro-e-Silva', Luiz Augusto Carneiro D’Albuquerque", Marina Rodrigues Garcia Silveira"', Patricia Zorzi ${ }^{\prime v}$, Jordan Bistafa Liu ${ }^{\vee}$, Daniel Tófoli Queiroz Campos ${ }^{\vee}$, João Paulo Victorinovı, Maria Cecília Jordani ${ }^{\text {VII }}$, Karina Dal Sasso Mendes ${ }^{\mathrm{VIII}}$, Paulo Roberto Barbosa Évora'x

'PhD, Full Professor, Surgery and Anatomy Department, Faculdade de Medicina de Ribeirão Preto - Universidade de São Paulo (FMRP-USP), Ribeirao Preto-SP, Brazil. Conception and design of the study, analysis and interpretation of data, manuscript writing, critical revision.

"PhD, Full Professor, Department of Gastroenterology, Medical School, USP, Sao Paulo-SP, Brazil. Interpretation of data, critical revision.

II'Graduate student, Ribeirao Preto Medical School, and Special Fellow PhD degree, Postgraduate Program in Public Health, Department of Preventive Medicine, Sao Paulo Medical School, USP, Sao Paulo-SP, Brazil. Technical procedures, acquisition of data.

IVGraduate student, FMRP-USP, Ribeirao Preto-SP. Technical procedures, acquisition of data.

${ }^{\vee}$ Graduate student, Faculdade de Medicina de Marília (FAMEMA), Marilia-SP, Brazil. Technical procedures; acquisition, analysis and interpretation of data.

V'BScN, USP, Ribeirão Preto College of Nursing, PAHO/WHO Collaborating Centre for Nursing Research Development, Ribeirao Preto-SP, Brazil. Interpretation of data.

VIIMaster, Biochemistry, Division of Digestive Surgery, Department of Surgery and Anatomy, FMRP-USP, Ribeirao Preto-SP, Brazil. Acquisition and interpretation of data.

VIIIRN, PhD, General and Specialized Nursing Department, USP, Ribeirao Preto College of Nursing, PAHO/WHO Collaborating Centre for Nursing Research Development, Ribeirao Preto-SP, Brazil. Interpretation of data.

IXPhD, Full Professor, Division of Thoracic and Cardiovascular Surgery, Department of Surgery and Anatomy, FMRP-USP, Ribeirao Preto-SP, Brazil. Conception and design of the study, manuscript writing, critical revision.

\section{Abstract}

Purpose: To analyze the effect of methylene blue (MB) therapy during the liver ischemiareperfusion injury (I/R) process.

Methods: Thirty-five male Wistar rats were used, (70\%) submitted to partial ischemia (IR) or not (NIR) (30\%) were obtained from the same animal. These animals were divided into six groups: 1) Sham (SH), 2) Sham with $M B(S H-M B)$; 3) I/R, submitted to 60 minutes of partial ischemia and 15 minutes of reperfusion; 4) NI/R, without I/R obtained from the same animal of group I/R; 5) I/R-MB submitted to I/R and MB and 6) NI/R-MB, without I/R. Mitochondrial function was evaluated. Osmotic swelling of mitochondria as well as the determination of malondialdehyde (MDA) was evaluated. Serum (ALT/AST) dosages were also performed. MB was used at the concentration of $15 \mathrm{mg} / \mathrm{kg}, 15$ minutes before hepatic reperfusion. Statistical analysis was done by the Mann Whitney test at $5 \%$.

Results: State 3 shows inhibition in all ischemic groups. State 4 was increased in all groups, except the I/R-MB and NI/R-MB groups. RCR showed a decrease in all I/R and NI/R groups. Mitochondrial osmotic swelling showed an increase in all I/R NI/R groups in the presence or absence of MB. About MDA, there was a decrease in $\mathrm{SH}$ values in the presence of $\mathrm{MB}$ and this decrease was maintained in the I/R group. AST levels were increased in all ischemic with or without $\mathrm{MB}$.

Conclusions: The methylene blue was not able to restore the mitochondrial parameters studied. Also, it was able to decrease lipid peroxidation, preventing the formation of reactive oxygen species.

Key words: Ischemia. Reperfusion. Methylene Blue. Mitochondria. Liver. Rats. 


\section{Introduction}

In several situations, the liver is submitted to periods of ischemia, as in hepatic trauma, transplantation, partial liver resections and circulatory shock. Blood deprivation causes damage to the liver, and restoration of blood flow, while allowing the supply of energy and removal of toxic metabolites, causes more severe effects than ischemia itself $f^{1,2}$. The ischemia and reperfusion injury $(\mathrm{I} / \mathrm{R})$ is related to local and systemic damage, which can result in loss or dysfunction of the organ, increased morbidity, and mortality of patients submitted to it. Thus, the search for new ways to mitigate this type of injury is justified ${ }^{1,2}$.

The damage caused by ischemia is related to the depletion of adenosine triphosphate (ATP), with activation of anaerobic metabolic pathways and the development of metabolic acidosis. Intracellular calcium accumulation, lysosomal rupture, and cell swelling also occur. On the other hand, reperfusion injury involves, in its early stage, mitochondrial dysfunction with the membrane permeability transition (TPM) of this organelle. In an intermediate phase, activation of the Kupffer cells occurs, with the release of more free radicals and pro-inflammatory cytokines. In the late phase, the lesion is marked by the activation of neutrophils ${ }^{3-6}$.

Some measures are studied in the possibility of reduction of I/R injury, such as surgical interventions, through preconditioning to ischemia, intermittent hepatic vascular occlusion, and hypothermic perfusion. Also, pharmacological measures can be used, such as antioxidant therapies, protease inhibitors, vasoactive drugs and magnesium sulfate $e^{4,7-9}$.

Methylene blue (MB) has been used in procedures such as liver transplantation. MB can block nitric oxide (NO) through the inhibition of guanylate cyclase and nitric oxide synthase (NOS), thereby reducing the formation of reactive nitrogen species and preventing cell damage ${ }^{10}$.

MB can block oxidant production by modulating the NO/guanylate cyclase pathway by reducing oxidative stress, since it may be an alternative electron acceptor. It also acts to neutralize the mitochondrial metabolism affected by mutagenic agents ${ }^{11}$. Also, it can anaerobically break hypoxanthine and xanthine in uric acid by attenuating the effect of hypoxanthine on ischemia, resulting in the formation of superoxide through reduction with molecular oxygen through xanthine oxidase and improve cytochrome oxidase activity $^{12,13}$.

Therefore, this investigation aims to verify if the $M B$ can exert therapeutic properties before the injury by $I / R$, analyzing its effects when administered prophylactically in livers submitted to partial ischemia of the liver.

\section{- Methods}

Thirty - five male Wistar rats weighing 200-300g were used, and in one mouse samples of blood and hepatic tissues were submitted to ischemia-reperfusion (I / R) and samples not submitted to ischemia-reperfusion (NI/R). The animals were anesthetized with a $20 \mathrm{mg} / \mathrm{ml}$ xylazine hydrochloride solution and ketamine hydrochloride $(50 \mathrm{mg} / \mathrm{ml})$ in a ratio of $1: 2$ and applied at $100 \mathrm{mg} / \mathrm{kg}$. The anesthesia was applied to the right gluteal muscle, and then the rat was placed in dorsal decubitus on a wooden support with its legs fixed in extension, followed by a trichotomy of the thoracoabdominal area. The surgical procedure was performed using a closed environment under controlled temperature $\left(23^{\circ} \mathrm{C}\right)$. The liver was exposed by a median laparotomy that extended from the lower third of the xiphoid appendix to the pubis and with the cerebral aneurysm clip after identification 
of the hepatic pedicle, the right medial, left medial and left lateral lobes were ischemiated for 60 minutes at the end of which, reperfused for 15 minutes. The right lateral lobes and the caudate lobe were not ischemia. Both the saline solution and the MB solution were applied to the inferior vena cava.

According to the technique described above14 the animals were divided into six groups containing 5 to 8 animals. The study design included: 1) Sham group (SH), samples submitted to surgical and anesthetic stress, but without ischemia-reperfusion with 0.5 $\mathrm{mL}$ saline; 2) group SHAM with methylene blue (SH-MB), samples submitted to the same surgical stress without ischemia-reperfusion with application of $0.5 \mathrm{~mL} \mathrm{MB}$; 3) I / R group, I / R samples in which $0.5 \mathrm{ml}$ of saline were injected 15 minutes before reperfusion; 4) NI / $\mathrm{R}$ group, samples submitted to surgical and anesthetic stress, that received $0.5 \mathrm{~mL}$ of saline but without I / $R$, of the same animal of group I / $\mathrm{R}$; 5) group I / R-MB samples submitted to I / R in which $0.5 \mathrm{ml}$ of $\mathrm{MB}$ were injected 15 minutes before reperfusion; 6) group $\mathrm{NI}$ / R-MB, samples submitted to surgical and anesthetic stress, that received $0.5 \mathrm{~mL}$ of $\mathrm{MB}$ but without I / $R$, of the same animal of group I / R-MB. The MB dose used was $15 \mathrm{mg} / \mathrm{kg}$ for each animal. The animals were sacrificed by total exsanguination through puncture through the inferior vena cava after total hepatectomy, according to the guidelines of the Animal Experimentation Ethics Committee of FMRP-USP.

At the time of sacrifice, hepatic tissue samples were collected for the study of mitochondrial respiration parameters $\left(\mathrm{O}_{2}\right.$ consumption rates in state 3 and 4 and respiratory control ratio - $\mathrm{RCR})^{15-17}$, a study related to the permeability of the internal mitochondrial membrane ${ }^{18}$ and oxidative stress (malondialdehyde -MDA) ${ }^{19}$. Blood samples were taken for the serum determination of alanine aminotransferase (ALT) and aspartate aminotransferase (AST) ${ }^{20}$.

\section{Preparation of mitochondria}

Isolation of liver mitochondria was performed by differential centrifugation at $4^{\circ} \mathrm{C}$. After the surgical procedure, the liver was immediately removed and placed in physiological saline in which it was washed. Then placed in medium containing $250 \mathrm{mM}$ sucrose, $1 \mathrm{mM}$ EGTA and $10 \mathrm{mM}$ Hepes$\mathrm{KOH}, \mathrm{pH} 7.2$ in which it was perforated and homogenized in Potter-Elvehjem through 3 cycles of 15 seconds with a 1-minute interval. The homogenate was centrifuged at $770 \mathrm{~g}$ for 5 minutes and the resulting supernatant centrifuged at $9800 \mathrm{~g}$ for 10 minutes. The obtained pellet was suspended in $10 \mathrm{ml}$ of medium containing $250 \mathrm{mM}$ sucrose, $0.3 \mathrm{mM}$ EGTA and $10 \mathrm{mM}$ Hepes- $\mathrm{KOH}, \mathrm{pH} 7.2$ and centrifuged at $4500 \mathrm{~g}$ for 15 minutes. The final pellet containing the isolated mitochondria was suspended in $0.5 \mathrm{~mL}$ of medium containing $250 \mathrm{mM}$ sucrose and $10 \mathrm{mM}$ Hepes- $\mathrm{KOH}, \mathrm{pH}$ 7.2 .

\section{Protein determination}

Mitochondrial proteins were
determined by the Coomassie Assay
(Coomassie plus - Bradford Assay ${ }^{\mathrm{Tm}}$ kit) at
$595 \mathrm{~nm}$ on a Versamax (Molecular Devices) microplate reader. The results obtained were expressed in $\mathrm{mg} / \mathrm{mL}$, using bovine serum albumin as a standard ${ }^{16}$.

\section{Oxygen consumption by mitochondria}

Mitochondrial respiration was monitored on a Hansatech-Oxygraph Plus oxygraph equipped with an oxygen electrode in medium containing $125 \mathrm{mM}$ sucrose, 65 $\mathrm{mM} \mathrm{KCl}, 1 \mathrm{mM} \mathrm{MgCl}, 2 \mathrm{mM} \mathrm{KH} \mathrm{PO}_{4}, 0.1$ $\mathrm{mM}$ EGTA and Hepes $10 \mathrm{mM} \mathrm{KOH}, \mathrm{pH}$ 7.4, 
energized with $5 \mathrm{mM}$ potassium succinate. The mitochondrial parameters evaluated were the rate of oxygen consumption in state 4 (basal respiration), the rate of oxygen consumption in state 3 (respiration activated by adenosine diphosphate - ADP) and respiratory control ratio (RCR), which indicates the degree of coupling between oxygen uptake and ADP phosphorylation $^{17}$.

\section{Determination of mitochondrial osmotic swelling}

The transition of the internal mitochondrial membrane permeability induced by $20 \mu \mathrm{M} \mathrm{CaCl}_{2}$ and $1 \mathrm{mM} \mathrm{KH}_{2} \mathrm{PO}_{4}$ was determined spectrophotometrically at $540 \mathrm{~nm}$ using a Beckman DU 640B spectrophotometer by decreasing the optical density $(\Delta D O)^{18}$.

\section{Determination of the MDA}

The colorimetric determination of MDA by its reaction with thiobarbituric acid was performed at $532 \mathrm{~nm}$ on a Versamax (Molecular Devices) microplate reader using 1,1,3,3-tetramethoxypropane (0 to $100 \mu \mathrm{M}$ ) as standard and the results obtained were expressed in $\mu \mathrm{M} / \mathrm{mg}$ of protein ${ }^{19}$.

\section{Determination of alanine aminotransferase and aspartate aminotransferase}

ALT and AST were determined by the kinetic method at $340 \mathrm{~nm}$ with the aid of the CELM SB-190 apparatus using a Labtest kit ${ }^{20}$.

\section{Statistical analysis}

The results were statistically analyzed by the non-parametric Mann-Whitney test with a significance level of $5 \%(P<0.05)$ between the groups. Statistical analyzes were performed with GraphPad Prism 6.02 software (GraphPad Software Inc, California).

\section{Results}

Figure 1 shows the values of oxygen consumption velocity by mitochondria in the presence of ADP (state 3), expressed in $\mathrm{nmol}$ of oxygen/min. There was a significant difference $(p<0.05)$ between $S H$ and $I / R, S H$ and I/R-MB, SH and NI/R-MB, SH-MB and I/R$M B, I / R$ and $N I / R$ groups, I/R and I/R-MB, NI/R and NI/R-MB and I/R-MB and NI/R-MB. State 3 showed inhibition in all ischemic groups about the Sham group, which did not occur in the non-ischemic contralateral portion of the same liver, demonstrating inhibition of the flow of electrons in the respiratory chain. In the presence of $M B$, the potentiation of this inhibition of state 3 was observed.

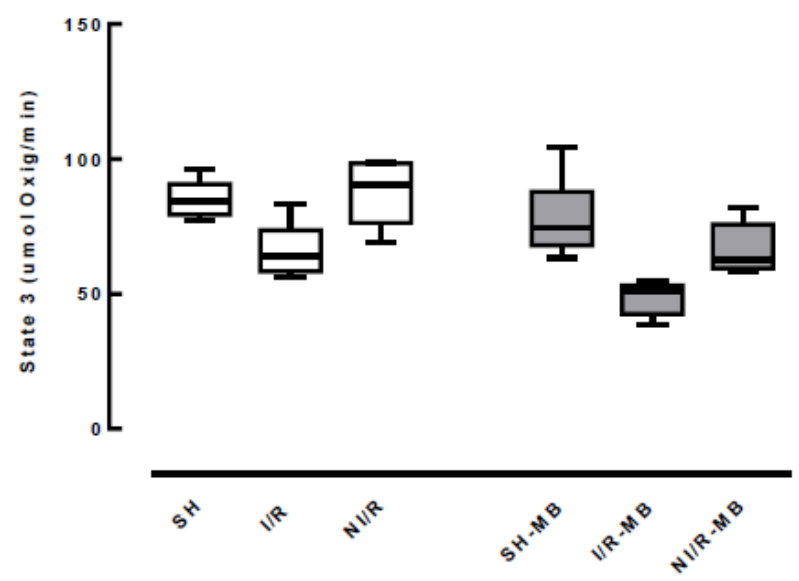

Figure 1 - Values of oxygen consumption velocity by mitochondria in the presence of ADP, expressed in $\mathrm{nmol}$ of oxygen/min. There was a significant difference $(p<0.05)$ between $S H$ and $I / R, S H$ and $\mathrm{I} / \mathrm{R}-\mathrm{MB}, \mathrm{SH}$ and $\mathrm{NI} / \mathrm{R}-\mathrm{MB}, \mathrm{SH}-\mathrm{MB}$ and $\mathrm{I} / \mathrm{R}-\mathrm{MB}, \mathrm{I} / \mathrm{R}$ and $\mathrm{NI} / \mathrm{R}$ groups, I/R and I/R-MB, NI/R and NI/R-MB and I/R-MB and NI/R-MB.

Figure 2 shows the values of oxygen consumption velocity by mitochondria in state 4 (basal), expressed in $\mathrm{nmol}$ of oxygen/min. There was a significant difference $(p<0.05)$ between $\mathrm{SH}$ and $\mathrm{SH}-\mathrm{MB}, \mathrm{SH}$ and $\mathrm{I} / \mathrm{R}, \mathrm{SH}$ and $\mathrm{NI} / \mathrm{R}, \mathrm{I} / \mathrm{R}$ and I/R-MB, NI/R and NI/R-MB groups. 


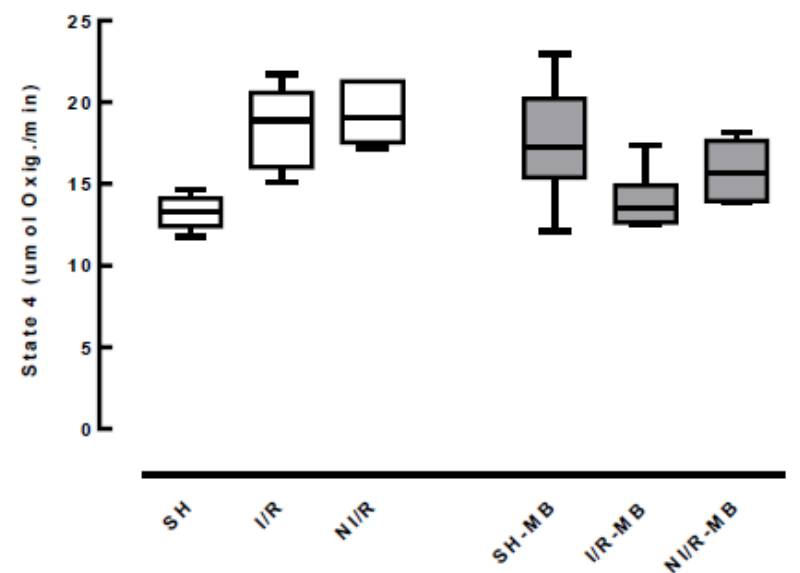

Figure 2 - Values of oxygen consumption velocity by mitochondria in state 4 (basal), expressed in nmol of oxygen $/ \mathrm{min}$. There was a significant difference $(p<0.05)$ between $\mathrm{SH}$ and $\mathrm{MB}, \mathrm{SH}$ and $\mathrm{I} / \mathrm{R}, \mathrm{SH}$ and $\mathrm{NI} / \mathrm{R}, \mathrm{I} / \mathrm{R}$ and $\mathrm{I} / \mathrm{R}-\mathrm{MB}$ and $\mathrm{NI} / \mathrm{R}$ and $\mathrm{NI} / \mathrm{R}-\mathrm{MB}$ groups.

Figure 3 shows the ratio between oxygen consumption velocity by mitochondria in state 3 and state 4 (RCR), presented a decrease in all ischemic and non-ischemic groups in the Sham group. The values show a significant difference $(p<0.05)$ between $\mathrm{SH}$ and $\mathrm{SH}-\mathrm{MB}, \mathrm{SH}$ and $\mathrm{I} / \mathrm{R}, \mathrm{SH}$ and $\mathrm{NI} / \mathrm{R}, \mathrm{SH}$ and I/R-MB, SH and NI/R-MB, SH-MB and I/R-MB, I/R groups and NI/R and I/R-MB and NI/R-MB.

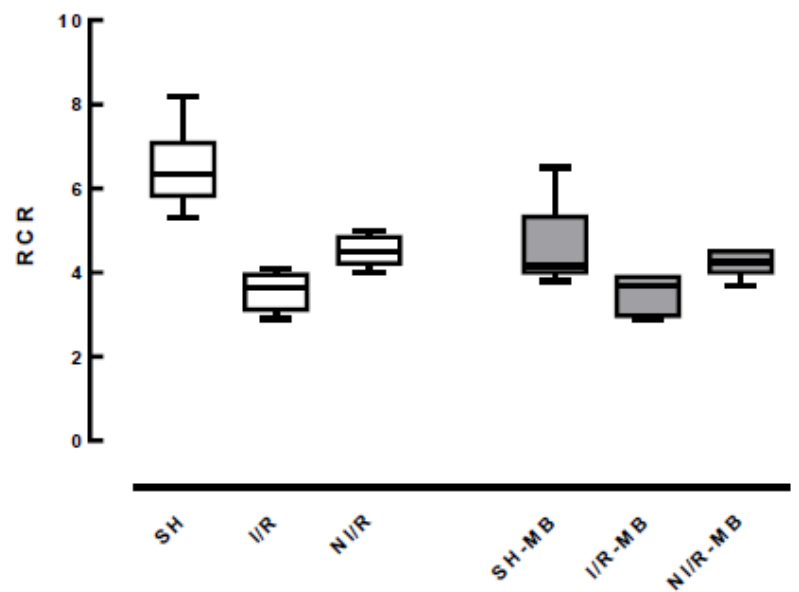

Figure 3-Values of the ratio of oxygen consumption velocity by mitochondria in state 3 and state 4 (respiratory control ratio - RCR). There was a significant difference $(p<0.05)$ between $S H$ and $M B$, $\mathrm{SH}$ and $\mathrm{I} / \mathrm{R}, \mathrm{SH}$ and $\mathrm{NI} / \mathrm{R}, \mathrm{SH}$ and $\mathrm{I} / \mathrm{R}-\mathrm{MB}, \mathrm{SH}$ and $\mathrm{NI} / \mathrm{R}-\mathrm{MB}, \mathrm{SH}-\mathrm{MB}$ and I/R-MB, I/R and NI/R and I/R$\mathrm{MB}$ and NI/R-MB.
The mitochondrial osmotic swelling, an essential marker of the structural and functional integrity of this organelle, showed an increase in all ischemic and non-ischemic groups about the $\mathrm{SH}$ group and this increase was maintained about the ischemic group when compared to the non-ischemic group, in the presence or not of MB. Figure 4 shows the values of $\mathrm{CaCl}_{2}$ and $\mathrm{KH}_{2} \mathrm{PO}_{4}$-induced mitochondrial osmotic swelling, expressed as optical density variation $(\triangle D O)$, there was a significant difference $(p$ $<0.05$ ) between $\mathrm{SH}$ groups and all other groups, $\mathrm{I} / \mathrm{R}$ and $\mathrm{NI} / \mathrm{R}, \mathrm{SH}$ and $\mathrm{SH}-\mathrm{MB}$ and I/R-MB and NI/R-MB.

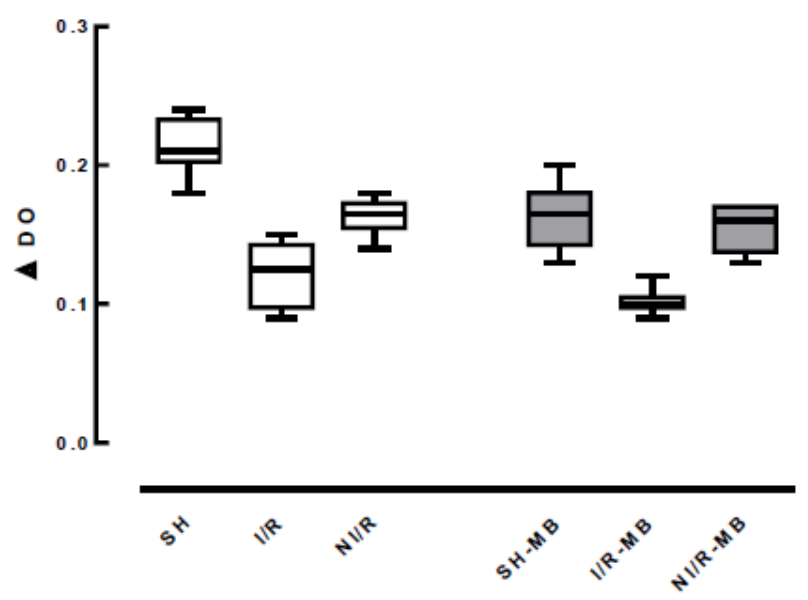

Figure 4 - Mitochondrial osmotic swelling values induced by $\mathrm{CaCl}_{2}$ and $\mathrm{KH}_{2} \mathrm{PO}_{4}$. There was a significant difference $(p<0.05)$ between $\mathrm{SH}$ groups and all other groups, I/R and $\mathrm{NI} / \mathrm{R}, \mathrm{SH}$ and $\mathrm{SH}-\mathrm{MB}$ and I/R-MB and NI/R-MB.

The results regarding the production of reactive species with thiobarbituric acid, determined by the MDA, showed a decrease in the values of the SH group in the presence of $\mathrm{MB}$ in the $\mathrm{SH}$ group, and this decrease was maintained in the I/R-MB group about the I/R group, showing that $M B$ treatment reduces lipid peroxidation. Figure 5 shows the MDA values expressed in $\mu \mathrm{M} / \mathrm{mg}$ protein $\left(\times 10^{-2}\right)$ with significant difference $(p<0.05)$ between $\mathrm{SH}$ and $\mathrm{SH}-\mathrm{MB}$ and between I/R and I/R-MB. 


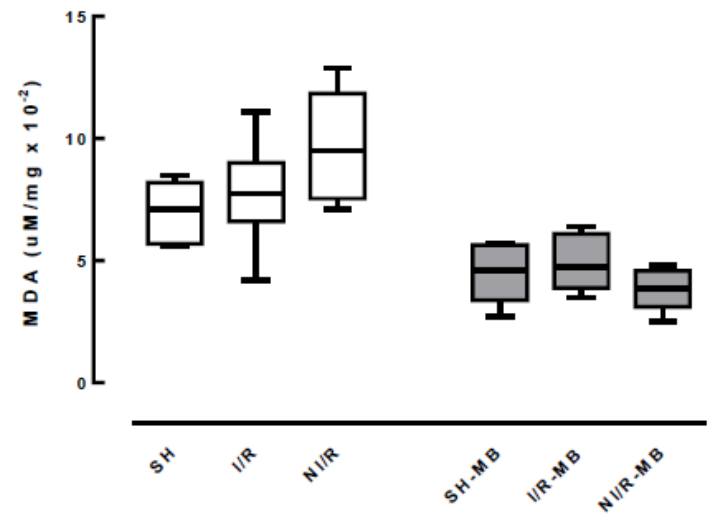

Figure 5 - MDA values expressed in $\mu \mathrm{M} / \mathrm{mg}$ protein $\left(x 10^{-2}\right)$. There was a significant difference between $\mathrm{SH}$ and $\mathrm{SH}-\mathrm{MB}$ and between $\mathrm{I} / \mathrm{R}$ and $\mathrm{I} / \mathrm{R}-\mathrm{MB}$.

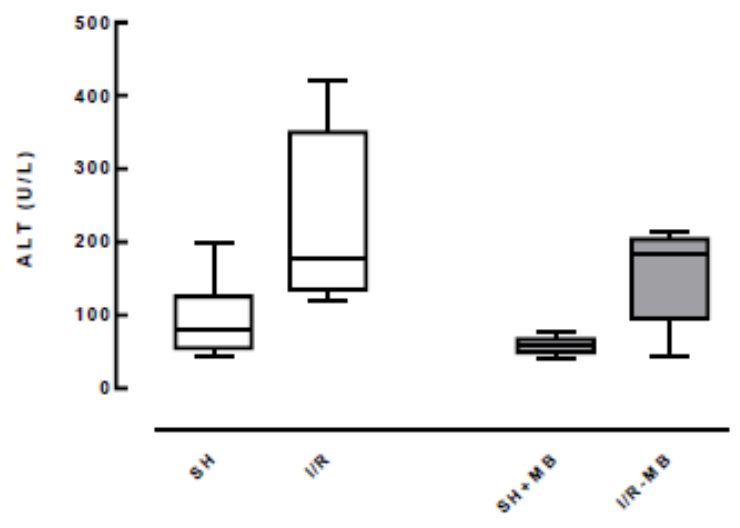

Figure 6 shows the serum values of liver enzymes ALT and AST, expressed as U/L. There was a significant difference $(p<0.05)$ between the $\mathrm{SH}$ and $\mathrm{I} / \mathrm{R}, \mathrm{SH}-\mathrm{MB}$ and $\mathrm{I} / \mathrm{R}, \mathrm{SH}-\mathrm{MB}$ and I/R-MB groups for both ALT and AST values. Regarding the AST values, there was also a difference between $\mathrm{SH}$ and I/R-MB, which did not occur about ALT, showing protection of MB.

Figure 6 - Serum values of liver enzymes ALT and AST expressed in U / L. There was a difference between SH and. I/R, SH-MB e. I/R, SH-MB, and I/R-MB for both ALT and AST values. Regarding the AST values, there was also a difference between $\mathrm{SH}$ and $\mathrm{I} / \mathrm{R}-\mathrm{MB}$.

\section{- Discussion}

Many results found in this study show a possible $\mathrm{I} / \mathrm{R}$ lesion, noted by differences between the sham groups and the non-I/R groups compared to those submitted to I/R.

The decrease in the rate of oxygen consumption in state 3 in the groups submitted to $\mathrm{I} / \mathrm{R}$ was potentialized by the treatment with $M B$, showing an inhibitory effect on this parameter, indicating a possible interaction of $\mathrm{MB}$ in the respiratory chain. The difference between the $\mathrm{SH}$ and $\mathrm{NI} / \mathrm{R}-\mathrm{MB}$ groups may also be explained by hemodynamic adaptation caused by $70 \%$ ischemia of the liver leaving a volumetric overload to the remaining 30\% 21 .

Regarding the state 4, although some groups present an increase in the rate of oxygen consumption, it can not be said that this increase is due to the action of $\mathrm{MB}$. This doubt report to the group I/R-MB, which presented values similar to the $\mathrm{SH}$ group and inferior to the I/R group, suggesting that the animals submitted to $I / R$ in the presence of $M B$ presented protection about the basal state of respiration, that is, their mitochondria are not decoupled. Regarding RCR, the decrease in values between the $\mathrm{SH}$ group and the other groups $(\mathrm{I} / \mathrm{R}, \mathrm{NI}, \mathrm{I} / \mathrm{R}$ $M B$ and $\mathrm{NI}-\mathrm{MB}$ ) is mainly due to the inhibition of the rate of oxygen consumption in state 3 , 
as explained above. However, the difference in RCR values found between the $\mathrm{SH}$ and $\mathrm{SH}$ $M B$ groups can be explained by the increase in the rate of oxygen consumption in state 4 , but these values dynamic overload occurs in nonischemic lobes.

In an in vitro study with MB Visarius and colleagues, demonstrated that in coupled mitochondria, the increase in $\mathrm{MB}$ concentration caused a decrease in the respiratory control ratio. Also, induced mitochondrial swelling, while in mitochondria decoupled, the $M B$ in dose-dependent concentrations stimulated respiration mitochondrial, showing that the action of $\mathrm{MB}$, depending on the conditions of mitochondria, can decouple oxidative phosphorylation or act as a mediator of electron transfer to stimulate mitochondrial respiration ${ }^{22}$.

It is already known that ischemia followed by reperfusion may lead to a permeability transition of the internal mitochondrial membrane causing swelling of the mitochondria ${ }^{23-24}$. In figure 4 we can observe that in the presence of $M B$ the osmotic swelling was maintained, showing that it was not able to protect the mitochondrial membrane. Also, the mitochondria of the SH$\mathrm{MB}$ and $\mathrm{NI}-\mathrm{MB}$ groups over the $\mathrm{SH}$ group also showed swelling, showing that $\mathrm{MB}$ was not able to protect membrane permeability changes.

Reactive oxygen and nitrogen species are generated in mitochondria during ischemia. Hypoxia inhibits oxidative phosphorylation of the cell and obstructs ATP production, causing disorders in mitochondrial $\mathrm{Ca}^{+2}, \mathrm{Na}^{+}$, and $\mathrm{H}^{+}$ions that may lead to the transition of mitochondrial membrane permeability. Oxidative stress plays an essential role in reperfusion injury ${ }^{23}$. In this study, we used the determination of MDA in order to evaluate oxidative stress and $\mathrm{MB}$ was able to prevent the production of reactive oxygen species, but without preventing changes in membrane permeability mitochondrial, showing the involvement of other factors in the process. In agreement with these results, other laboratory studies with $\mathrm{MB}$ at the same dose $(15 \mathrm{mg} / \mathrm{kg})$ given 15 minutes before ischemia were also able to reduce lipid peroxidation, showing that this protective effect occurs both before ischemia and reperfusion ${ }^{14}$. Some studies show that MB prevents the production of reactive oxygen species by acting as an alternative receptor for xanthine oxidase electrons, competing with molecular oxygen for the transfer of electrons and preventing the formation of superoxide. Also, methylene blue inhibits the activation of soluble guanylate cyclase, thereby significantly reducing the peripheral effects of NO without detriment to other beneficial effects of this substance, such as inducing the cytotoxicity of macrophages against specific microorganisms and specific tumor cells ${ }^{12,25}$.

An increase in serum AST levels was observed in all ischemic groups in the $\mathrm{SH}$ group, both in animals submitted to MB treatment or not. However, about ALT, there was a protection of the MB of the animals submitted to I/R about the $\mathrm{SH}$, showing possible specific protection for the hepatic damage ${ }^{26}$. However, the experimental study of Rosique et al. ${ }^{10}$ regarding $\mathrm{MB}$ in livers of rabbits subjected to ischemic burn and reperfusion showed no attenuation of AST and ALT elevation, indicating that MB did not protect the liver parenchyma. Regarding the hemodynamic instability caused by IR, it found better results with an infusion of $\mathrm{MB}$ after reperfusion, that is, as treatment, and not as prophylaxis, suggesting that the effect of $M B$ is more effective after injury. The results of the use of the $M B$ in patients undergoing liver transplantation are conflicting. While the study by Koelzow et al. ${ }^{27}$ with 36 patients showed attenuation of the hemodynamic changes caused by IR in the Fukazawa and Pretto study with 715 patients, MB was not able to prevent postoperative hypotension the use of vasopressors and the postoperative function of the graft ${ }^{28}$. 


\section{- Conclusions}

At the concentration used and after the installation of ischemia, the MB was not able to restore the mitochondrial parameters and processes studied, except for decoupling protection. However, it was able to decrease lipid peroxidation, preventing the formation of reactive oxygen species, as well as attenuating ALT levels, preventing greater I/R lesions.

\section{References}

1. Miranda LEC, Viaro F, Ceneviva R, Evora PRB. As bases experimentais da lesão por isquemia e reperfusão do fígado: revisão. Acta Cir Bras. 2004;19(1):1-12. doi: 10.1590/ S0102-86502004000100001

2. Evora PRB, Silva Júnior OC. Vasoplegic endothelial dysfunction in orthotopic transplantation. Acta Cir Bras. 2016;31(1):14.doi:10.1590/S0102-86502016001300001.

3. Fondevila C, Hessheimer AJ, Taurá P, Sánchez O, Calatayud D, de Riva N, Muñoz J, Fuster J, Rimola A, García-Valdecasas JC. Portal hyperperfusion: mechanism of injury and stimulus for regeneration in porcine small-for-size transplantation. Liver Transpl. 2010;16(3):364-74. doi: 10.1002/It.21989.

4. Glantzounis GK, Salacinski HJ, Yang W, Davidson BR,SeifalianAM. The contemporary role of antioxidant therapy in attenuating liver ischemia-reperfusion injury: a review. Liver Transpl. 2005;11(9):1031-47. doi: 10.1002/lt.20504.

5. Guan, LY, Fu PY, Li PD, Li ZN, Liu HY, Xin MG, Li W. Mechanisms of hepatic ischemiareperfusion injury and protective effects of nitric oxide. World J Gastrointest Surg. 2014;6(7):122-8. doi: 10.4240/wjgs. v6.i7.122.

6. Fiegel $M$, Cheng $S$, Zimmerman $M$, Seres T, Weitzel NS. Postreperfusion syndrome during liver transplantation. Semin Cardiothorac Vasc Anesth. 2012;16(2):10613. doi: $10.1177 / 1089253212444791$.

7. Casillas-Ramírez A, Mosbah IB, Ramalho F, Roselló-Catafau J, Peralta C. Past and future approaches to ischemia-reperfusion lesion associated with liver transplantation. Life Sci. 2006;79(20):1881-94. doi: 10.1016/j. Ifs.2006.06.024.
8. Li J, Li RJ, Lv GY, Liu HQ. The mechanisms and strategies to protect from hepatic ischemiareperfusion injury. Eur Rev Med Pharmacol Sci. 2015;19(11):2036-47. PMID: 26125267.

9. Siniscalchi A, Gamberini L, Laici C, Bardi T, Ercolani G, Lorenzini L, Faenza S. Post reperfusion syndrome during liver transplantation: from pathophysiology to therapy and preventive strategies. World J Gastroenterol. 2016;22(4):1551. doi: 10.3748/wjg.v22.i4.1551.

10. Rosique RG, Rosique MJ, Rosique IA, Tirapelli LF, Castro e Silva O Jr, dos Santos JS, Evora PR. Effect of methylene blue on the hemodynamic instability resulting from liver ischemia and reperfusion in rabbits. Transplant Proc. 2011;43(10):3643-51. doi: 10.1016/j.transproceed.2011.08.108.

11.Collange, $\mathrm{O}$, Charles AL, Bouitbir J, Chenard MP, Zoll J, Diemunsch P, Thaveau F, Chakfé N, Piquard F, Geny B. Methylene blue protects liver oxidative capacity after gut ischaemiareperfusion in the rat. Eur J Vasc Endovasc Surg. 2013;45(2):168-75. doi: 10.1016/j. ejvs.2012.11.011.

12.Salaris SC, Babbs CF, Voorhees WD. Methylene blue as an inhibitor of superoxide generation by xanthine oxidase: a potential new drug for the attenuation of ischemia/reperfusion injury. Biochem. Pharmacol.1991;42(3):499-506. PMID: 1650213.

13.Di Y, He YL, Zhao T, Huang X, Wu KW, Liu SH, Zhao YQ, Fan M, Wu LY, Zhu LL. Methylene blue reduces acute cerebral ischemic injury via the induction of mitophagy. Mol Med. 2015;21(1):420-9. doi: 10.2119/ molmed.2015.00038.

14.de Almeida TN, Victorino JP, Liu JB, Tófoli DQC, Graf C, Jordani MC, d'Albuquerque LAC, Mendes KDS, Castro-E-Silva O. Effect of hepatic preconditioning with the use of methylene blue on the liver of wistar rats submitted to ischemia and reperfusion. Transplant Proc. 2018;50(3):841-7. doi: 10.1016/j.transproceed.2018.02.002.

15.Pedersen PL, Greenawalt JW, Reynafarje B, Hullihen J, Decker GL, Soper JW, Bustamente E. Preparation and characterization of mitochondria and submitochondrial particles of rat liver and liver-derived tissues. Methods Cell Biol. 1978;20:411-81. PMID: 151184. 
16.Bradford MM. A rapid and sensitive method for the quantitation of microgram quantities of protein utilizing the principle of proteindye binding. Anal Biochem. 1976;72(12):248-54. PMID: 942051.

17.Chance B, Williams GR. The respiratory chain and oxidative phosphorylation. Adv Enzymol Relat Subj Biochem. 1956;17:65134. PMID: 13313307.

18.Zoratti M, Szabò I. The mitochondrial permeability transition. Biochem Biophys Acta. 1995;1241:139-76. PMID: 7640294.

19.Lapenna D, Ciofani G, Pierdomenico SD, Giamberardino MA, Cuccurullo F. Reaction conditions affecting the relationship between thiobarbituric acid reactivity and lipid peroxidesin human plasma. Free Radic Biol Med. 2001;31(3):331-5. PMID: 11461770.

20.Henry RJ, Chiamori N, Golub OJ, Berkman $\mathrm{S}$. Revised spectrophotometric methods for the determination of glutamate oxaloacetic transaminase, glutamic pyruvate transaminase and lactic acid dehydrogenase. Am J Clin Pathol. 1960;(34):381-9. PMID: 13713438.

21.Díaz-Juárez J, Rivera-Valerdi L, Bernal-Cerrillo DE, Hernández-Muñoz R. Predominance of released mitochondrial enzymes by partial hepatectomy-induced rat regenerating liver is controlled by hemodynamic changes and not related to mitochondrial damage. Scand J Gastroenterol. 2006;41(2):223-33. doi: $10.1080 / 00365520510024142$.
22.Visarius TM, Stucki JW, Lauterburg BH. Stimulation of respiration by methylene blue in rat liver mitochondria. FEBS Lett. 1997;412(1):157-60. PMID: 9257711.

23. Handy $D E$, Loscalzo J. Redox regulation of mitochondrial function. Antioxid Redox Signal. 2012;16(11):1323-67. doi: 10.1089/ ars.2011.4123.

24.Vilalva KH, Figueira RL, Silveira M, Graf C, Gonçalves FL, Sbragia L, Gomes MC, Mumic F, Vollet-Filho D, Bagnato VS, d'Albuquerque LAC, Castro-e-Silva O. Prophylactic application of laser light restores L-FABP expression in the livers of rats submitted to partial ischemia. Clinics (São Paulo). 2018;73:e113. doi: 10.6061/clinics/2018/e113.

25.Knobel E. Óxido nítrico e sepse. Arq Bras Cardiol. 1996;67(4):263-6.

26.Giannini EG, Testa R, Savarino V. Liver enzyme alteration: a guide for clinicians. CMAJ. 2005;172(3):367-79. doi: 10.1503/ cmaj.1040752.

27. Koelzow H, Gedney JA, Baumann J, Snook NJ, Bellamy MC. The effect of methylene blue on the hemodynamic changes during ischemia reperfusion injury in orthotopic liver transplantation. Anesth Analg. 2002;94(4):824-9. PMID: 11916779.

28. Fukazawa K, Pretto EA. The effect of methylene blue during orthotopic liver transplantation on post reperfusion syndrome and postoperative graft function. J Hepatobiliary Pancreat Sci. 2011;18(3):40613. doi: 10.1007/s00534-010-0344-7.

\section{Correspondence:}

Prof. Dr. Orlando Castro-Silva

Hospital das Clínicas de Ribeirão Preto, Departamento de Cirurgia e Anatomia

Avenida Bandeirantes 3900, Campus

Universitário

14049-900 Ribeirão Preto - SP Brasil

Tel.: (55 16)3602-2593

orlando@fmrp.usp.br

Received: Aug 03, 2018

Review: Oct 06, 2018

Accepted: Nov 09, 2018
Conflict of interest: none

Financial sources: FAPESP, CAPES, CNPq
${ }^{1}$ Research performed at Liver Transplantation Unit, Surgery and Anatomy Department, Faculdade de Medicina de Ribeirão Preto Universidade de São Paulo (FMRP-USP), and Department of Gastroenterology, Medical School, USP, Sao Paulo-SP, Brazil. 